\title{
Masahisa Fujita and The Transformation of Urban Economics
}

Paul Krugman

Masa Fujita is a quiet economist - articulate and funny in person, but never one for dramatic gestures or flashy presentations. His work and influence over the years have built gradually, without at first attracting widespread notice beyond urban economists. But over time he, more than anyone else, has transformed the field.

If there is an overarching theme in Masa's work, it is "escape from von Thünen." Let me explain.

The von Thünen model of land use and land rent has, justifiably, exerted a powerful influence on how economists think about location, especially within cities. The basic idea is that of a single urban center, with costly transportation of goods to that center; given varying costs of transportation, this leads to a predictable relationship between land rents, land use, and distance from the center. Once Alonso realized that the same basic framework could be applied to commuting to a city center rather than transporting goods to a central city, we had a ready-made way to think about urban structure - and this way of thinking remains useful to this day.

Yet the "concentric circles" approach is, in some ways, deeply unsatisfying - and arguably also of diminishing relevance. First of all, why is there a city center and/or a central city? Presumably some form of agglomeration economies is responsible, but shouldn't these agglomeration economies be part of the model? Second, how do we know that there is just one center? In reality, cities have become less monocentric over time, with some metropolitan areas having no one dominant central business district metro Los Angeles, to take the most famous example, has two major centers with employment in the hundreds of thousands, and several smaller centers with collective employment on the same scale. Finally, what's the nature of those external economies that are only implicit in von Thünen and modern urban theory?

If you want answers to these questions, study Fujita.

I won't try to offer any kind of comprehensive overview of Masa's work here; let me, instead, briefly describe three papers that deeply influenced my own thinking in this area. 
First, Fujita and Ogawa (1982). This was and remains an astonishingly ambitious and sophisticated paper. It takes the idea of positive spillovers between firms that fade out gradually with distance, derives a concept of spatial equilibrium, and shows that monocentric cities can happen, but so can polycentric, Los-Angeles-type urban areas. Nobody who reads that paper can ever be fully comfortable again with the arbitrary assumption that there is just one central business district.

Second, Fujita (1988). This was the dawn of the "new economic geography" approach in which external economies are derived from the interaction of economies of scale at the level of the firm with transport costs. One way to think about a lot of the work Masa did with Tony Venables and me after 1990 was that we were trying to integrate the insights of Fujita 1988 with those of Fujita and Ogawa 1982.

Finally, Fujita and Mori (1996). This paper took the key step of showing how the self-organizing character of economic geography interacts with the givens of natural geography, how natural ports serve as the catalysts of city formation. Every time I talk about the history of New York, I have Fujita and Mori in the back of my mind.

These papers, together with the rest of the Fujita canon, played a crucial role in creating the modern view of cities - their internal structure and their role in the wider economy. Nor was that Masa's only channel of influence: we should also remember that Masa has been a beloved and influential teacher to many students over the years, spreading his insights through personal communication as well as the printed word.

I count myself very fortunate first to have encountered Masa's writing, then to have had the wonderful opportunity to work with him. So let's honor his work - the work, as I said, of a quiet economist, but one whose greatness shines through.

\section{References}

Masahisa Fujita and Hideaki Ogawa, "Multiple equilibria and structural transition of non-monocentric urban configurations", Regional Science and Urban Economics, 1982, vol. 12, issue 2, pages 161-196.

Masahisa Fujita, "A monopolistic competition model of spatial agglomeration : Differentiated product approach" Regional Science and Urban Economics Volume 18, Issue 1, February 1988, Pages 87-124

Masahisa Fujita and Tomoya Mori, "The role of ports in the making of major cities: Self-agglomeration and hub-effect", Journal of Development Economics Volume 49, Issue 1, April 1996, Pages 93-120 